$\underset{\text { Clinical }}{\text { nephron }}$

Practice
Nephron 2015;131:191-201

DOI: $10.1159 / 000441151$
Received: June 12, 2015

Accepted: September 15, 2015

Published online: October 21, 2015

\title{
Hepatorenal Acute Kidney Injury and the Importance of Raising Mean Arterial Pressure
}

\author{
Juan Carlos Q. Velez ${ }^{\mathrm{a}}$ Manish Kadian ${ }^{\mathrm{a}}$ Margarita Taburyanskaya ${ }^{\mathrm{d}}$ \\ Nicole M. Bohm ${ }^{\text {e }}$ Tracie A. Delay ${ }^{d}$ Nithin Karakala ${ }^{a}$ Don C. Rockey ${ }^{c}$ \\ Paul J. Nietert ${ }^{f}$ Andrew J. Goodwin ${ }^{b}$ Timothy P. Whelan ${ }^{b}$ \\ Divisions of a Nephrology, ${ }^{b}$ Pulmonary Medicine and ${ }^{\mathrm{C}}$ Gastroenterology and Hepatology, and Department of

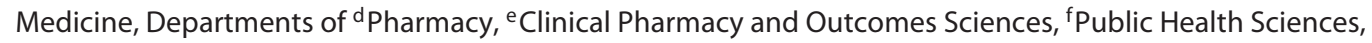 \\ Medical University of South Carolina, Charleston, S.C., USA
}

\section{Key Words}

Cirrhosis $\cdot$ Norepinephrine $\cdot$ Midodrine $\cdot$ Octreotide $\cdot$ Acute kidney injury $\cdot$ Hepatorenal $\cdot$ Vasoconstrictors $\cdot$ Arterial blood pressure

\begin{abstract}
Background: The efficacy of vasoconstrictors in hepatorenal syndrome (HRS) is variable. We hypothesized that the effectiveness of vasoconstrictor therapy in improving kidney function ultimately relates to the magnitude of the achieved mean arterial pressure (MAP) increase. Methods: A retrospective study was conducted to identify cirrhotic individuals treated with vasoconstrictors for acute kidney injury (AKI) presumably caused by HRS to examine the relationship between change in MAP and change in serum creatinine $(\mathrm{s} C \mathrm{r})$ using multivariate mixed linear regression. Results: Among 73 patients treated with midodrine/octreotide, change in MAP inversely correlated with change in $\mathrm{sCr}(\mathrm{p}=0.0005)$. The quartile with the greatest increase in MAP $(+15.9$ to +29.4 $\mathrm{mm} \mathrm{Hg}$ ) was associated with a subsequent absolute decrease in $\mathrm{s} C r$. The strength of the correlation increased when the analysis was restricted to those who met the HRS criteria $(\mathrm{n}=27, \mathrm{p}=0.002)$, where the third $(+5.3$ to $+15.6 \mathrm{~mm} \mathrm{Hg})$
\end{abstract}

and fourth (+15.9 to $+20.9 \mathrm{~mm} \mathrm{Hg}$ ) quartiles of MAP change were associated with a decrease in $\mathrm{s} C \mathrm{r}$. A similar but stronger correlation was found among 14 patients treated with norepinephrine either after failing midodrine/octreotide $(n=$ 10 ) or de novo $(n=4 ; p=0.002)$, where a rise in MAP of +19.2 to $25 \mathrm{~mm} \mathrm{Hg}$ was associated with a larger reduction in $\mathrm{sCr}$. Associations remained significant after adjustment for baseline parameters. Conclusions: The magnitude of MAP rise during HRS therapy with midodrine/octreotide or norepinephrine correlated with a reduction in $\mathrm{s} C \mathrm{r}$ concentration. Our results suggest that achieving a pre-specified target of MAP increase might improve renal outcomes in hepatorenal AKI.

(c) 2015 S. Karger AG, Basel

\section{Introduction}

Hepatorenal syndrome (HRS) type 1 is an ominous complication of cirrhosis with portal hypertension characterized by acute, rapid and severe deterioration of kidney function that is associated with significant morbidity and mortality $[1,2]$. Current pharmacotherapy for HRS centers on the use of vasopressors including vasopressin

\section{KARGER 125}

(c) 2015 S. Karger AG, Basel

$1660-8151 / 15 / 1313-0191 \$ 39.50 / 0$

E-Mail karger@karger.com

www.karger.com/nef
Dr. Juan Carlos Q. Velez

Department of Medicine, Division of Nephrology, Medical

University of South Carolina, 96 Jonathan Lucas Street

Clinical Sciences Building, Room 826F, Charleston, SC 29425 (USA)

E-Mailvelezj@musc.edu 
[3] and its analogue terlipressin [4-6], norepinephrine [7-9] and the $\alpha_{1}$-agonist/somatostatin analog combination therapy midodrine/octreotide [10-13]. The rationale for the use of vasopressors in HRS is to oppose a state of splanchnic vasodilatation with the overarching goal of increasing the effective circulatory volume thereby increasing kidney perfusion $[14,15]$.

Terlipressin has been the preferred drug for the treatment of HRS in Europe, Canada and Asia; however, the 2 largest randomized controlled clinical trials ever conducted to evaluate the efficacy of terlipressin in HRS failed to reach the primary end point of decrease in serum creatinine ( $\mathrm{sCr}$ ) level to $\leq 1.5 \mathrm{mg} / \mathrm{dl}$ sustained for at least $48 \mathrm{~h}$ without death, dialysis or HRS relapse by day 14 [16, 17]. Because terlipressin is not approved for use in the United States, the combination of midodrine/octreotide is widely used as first-line treatment for HRS in the United States and is recommended by the American Academy for the Study of Liver Diseases [18]. In a seminal study, the combination of midodrine/octreotide was effective in reversing HRS in 3 out of 5 (60\%) of the subjects compared to 0 out of 8 who were treated with low-dose dopamine [10]. Subsequently, 2 retrospective studies also suggested a potential benefit of the midodrine/octreotide combination $[11,13]$. However, a lower efficacy rate for midodrine/octreotide has been reported more recently [19], a finding that is consistent with our anecdotal clinical observations of poor success rate of this treatment modality.

A meta-analysis of 37 cohorts from 21 studies assessing the efficacy of various vasoconstrictors in HRS revealed that regardless of the drug utilized or baseline value of mean arterial pressure (MAP), improvement in kidney function during HRS therapy strongly correlated with the magnitude of the concomitant rise in MAP [20]. This observation agreed with other contemporary studies that reported a similar relationship between MAP gain and positive renal outcome $[21,22]$. However, the metaanalysis was conducted without access to individual patient data. Thus, we sought to corroborate the relationship between MAP gain and improvement in kidney function by accessing individual patient data in a cohort of HRS subjects treated with vasoconstrictors in our institution. Because of published evidence showing comparable efficacy to that of terlipressin $[23,24]$, norepinephrine has become an attractive alternative to midodrine/ octreotide. Therefore, both therapeutic approaches were examined independently in this study. We hypothesized that a relationship between attained MAP gain and subsequent decrease in $\mathrm{sCr}$ concentration would be present in cirrhotic subjects treated with either midodrine/octreotide combination or norepinephrine for acute kidney injury (AKI) presumed to be due to HRS.

\section{Methods}

\section{Subjects and Study Design}

This was a single-center retrospective study conducted at the Medical University of South Carolina (MUSC). The primary objective of the study was to determine the relationship between changes in MAP attained during treatment of HRS with either midodrine/octreotide combination or norepinephrine and changes in kidney function as determined by a change in $\mathrm{sCr}$ concentration. The current practice at the MUSC is to treat patients with HRS with midodrine/octreotide or norepinephrine; other vasoconstrictors are not used to treat HRS. Upon approval by the Institutional Review Board at the MUSC and in accordance with the Declaration of Helsinki, we queried institutional electronic medical records to search for adult patients 18-80 years of age with a discharge diagnosis of cirrhosis who experienced HRS and/or AKI (or acute renal failure) during hospitalization between December 2008 and December 2013, according to the International Classification of Diseases-9 coding. We abstracted data from those who received a combination of midodrine/octreotide or norepinephrine during their hospital stay. Physician documentation must have explicitly stated that the indication for intravenous vasopressors was for HRS in order to be included in the primary cohort. Subjects were excluded for the following reasons: duration of therapy less than $24 \mathrm{~h}$, development of shock or death within the first $24 \mathrm{~h}$ of initiation of therapy, use of (or - addition of - for norepinephrine-treated patients) intravenous vasopressor or inotrope preceding or administered during therapy, renal replacement therapy preceding or administered during therapy, prior history of transjugular intrahepatic portosystemic shunt, autonomic dysfunction or concomitant malignancy.

\section{Clinical Data Collection and Measured Variables}

Demographic, clinical and laboratory data were collected for each subject. The Model for End-Stage Liver Disease (MELD) score was calculated based on parameters obtained on the day of therapy initiation. Up to 12 values of automated cuff systolic blood pressure (SBP) and diastolic blood pressure (DBP) were collected per day for each patient. Values closest to 2-hour intervals were selected. These values were used to calculate a daily mean MAP, according to the equation $\mathrm{MAP}=(\mathrm{SBP}+2(\mathrm{DBP})) / 3$. Dosing of midodrine/octreotide, norepinephrine, albumin and other medications were reviewed. The titration of therapy was considered inadequate if a minimal rise in MAP of $15 \mathrm{~mm} \mathrm{Hg}$ was not observed, unless the maximum dose was reached, that is, midodrine $15 \mathrm{mg}$ thrice a day, octreotide $200 \mu \mathrm{g}$ twice a day or norepinephrine 80 $\mu \mathrm{g} / \mathrm{min}$. Daily sCr was collected from the first morning blood draw. The sCr obtained in the morning (closest to 4:00-5:00 a.m.) of the day of initiation of vasoconstrictor therapy was considered the baseline, whereas baseline MAP was extracted from the preceding day, in order to examine the clinical effect of MAP change on sCr measured the following day. Data collection was stopped when therapy drug was discontinued, a second vasopressor or renal replacement therapy was initiated, a patient underwent a TIPS 
procedure, died or was discharged from the hospital. A fraction of patients were switched from midodrine/octreotide to norepinephrine. For those patients, data from each treatment period were collected and analyzed independently. No patient was switched from norepinephrine to midodrine/octreotide. No dual therapy was included in this study.

To verify the accuracy of the diagnosis of HRS adjudicated by the treating physicians, medical records were reviewed to determine if the identified subjects met the 2007 International Ascites Club (IAC) criteria [25]. This definition requires failure to respond to volume expansion with intravenous albumin. To account for a hospital policy restricting the use of intravenous albumin, volume expansion with intravenous crystalloid solution was accepted, as outlined in the 1996 definition of HRS [26]. Accordingly, either $1 \mathrm{~g} / \mathrm{kg}$ (or $100 \mathrm{~g}$ ) of intravenous albumin or $1.5 \mathrm{l}$ of normal saline had to be given to each patient before the diagnosis of HRS was made and within $48 \mathrm{~h}$ prior to initiation of treatment with a vasoconstrictor. Otherwise, the remainder of the IAC criteria was strictly followed. Patients who met the IAC criteria were categorized as definite HRS. Otherwise, the entire cohort of all patients with adjudicated HRS diagnosis was categorized as presumed HRS or hepatorenal AKI.

\section{Statistical Analysis}

To test whether there was a significant correlation between subjects' change in MAP during their hospitalizations and their change in sCr, a series of generalized linear mixed models (GLMMs) were used. GLMMs are ideal for modeling repeated measures obtained within the same subjects over time [27], as they account for the fact that measurements within subjects tend to be strongly correlated with one another. Subjects' baseline sCr values were subtracted from their daily values in order to obtain daily sCr change scores for each subject. Subjects' baseline MAP values were then subtracted from their daily MAP averages to obtain daily MAP change scores. Within the GLMMs, subjects' daily sCr change scores served as the dependent variable, and their MAP change (with a 1 day lag time) served as the primary independent variable. Baseline sCr and MAP values were included as covariates, as were the subjects' baseline MELD scores and the time elapsed between the value and the baseline measurement. The GLMMs included random effects for subjects' intercepts and slopes and incorporated an unstructured covariance structure, since this approach yielded the best model fit according to the Akaike Information Criteria [28]. GLMMs were created for the presumed HRS and the definite HRS cohorts treated with midodrine/octreotide and for the cohort who received norepinephrine. Having 73 patients available for the primary analyses provided $80 \%$ power to detect whether changes in MAP explained as little as $11 \%$ of the variation in sCr changes. All analyses were performed using SAS statistical software, version 9.4 (Cary, N.C., USA).

\section{Results}

\section{Patient Characteristics}

Figure 1 shows the flow chart that was followed for patient identification. Of 164 patients with cirrhosis and presumed HRS as a cause of AKI who received midodrine/octreotide, 91 were excluded (primarily due to con- comitant shock or dialysis or duration of therapy $<24 \mathrm{~h}$ ), leaving 73 patients for the primary analysis. Sixteen of those 73 patients were switched from midodrine/octreotide to norepinephrine due to failure to improve kidney function during midodrine/octreotide combination, but 6 were excluded, leaving 10 for analysis for the norepinephrine cohort. Of 5 patients who received norepinephrine as primary treatment for HRS without prior midodrine/octreotide therapy, 1 was excluded, leaving 4 additional patients, for a total of 14 patients in the norepinephrine cohort (fig. 1). The baseline characteristics of the study participants are shown in table 1. Because all study patients exhibited a rapid deterioration of kidney function prior to therapy, they were deemed compatible with a type 1 HRS diagnosis.

\section{Midodrine/Octreotide Cohort}

For the 73 subjects with presumed HRS who received treatment with midodrine/octreotide, the median total daily dose of midodrine was $22 \mathrm{mg}$ (range 15-45), and the median total daily dose of octreotide was $380 \mu \mathrm{g} /$ day (range 200-400). In $88 \%$ of the patients, the starting doses were $5 \mathrm{mg}$ thrice a day orally and $100 \mu \mathrm{g}$ twice a day subcutaneously, for midodrine and octreotide, respectively. The primary analyses to assess for a correlation between change in MAP and change in $\mathrm{sCr}$ are presented in table 2. Results are provided for the entire cohort (i.e., the presumed HRS cohort, $\mathrm{n}=73$ ) as well as the definite HRS subset $(\mathrm{n}=27)$. The observation period had a median duration of 6 days (interquartile range [IQR] 4-10) for the presumed HRS group and 6 days (IQR 4-11) for the definite HRS. After adjusting for relevant covariates ( $\mathrm{sCr}$ at baseline, MAP at baseline, day of therapy and baseline MELD score), there was a significant association between MAP change from baseline and change in $\mathrm{sCr}$ from baseline (presumed HRS: beta $-0.014, \mathrm{p}=0.0005$; definite HRS: beta $-0.037, \mathrm{p}=0.002$ ). Beta estimates reflect the estimated change in $\mathrm{sCr}$ associated with a 1 unit increase in the independent variable, with negative values indicating decreases in $\mathrm{sCr}$ and positive values indicating increase in sCr. In this case, a $10 \mathrm{~mm} \mathrm{Hg}$ increase in MAP was associated with an average reduction in $\mathrm{sCr}$ of 0.14 $\mathrm{mg} / \mathrm{dl}$ in the presumed HRS cohort and of $0.37 \mathrm{mg} / \mathrm{dl}$ in the definite HRS cohort. Baseline creatinine, baseline MAP, MELD score and day of HRS therapy were not predictive of creatinine change. The absolute value of the beta estimate was larger in the definite HRS cohort than in the presumed HRS cohort, suggesting that the observed correlation was stronger in the definite HRS cohort. When subjects were grouped into quartiles with re- 


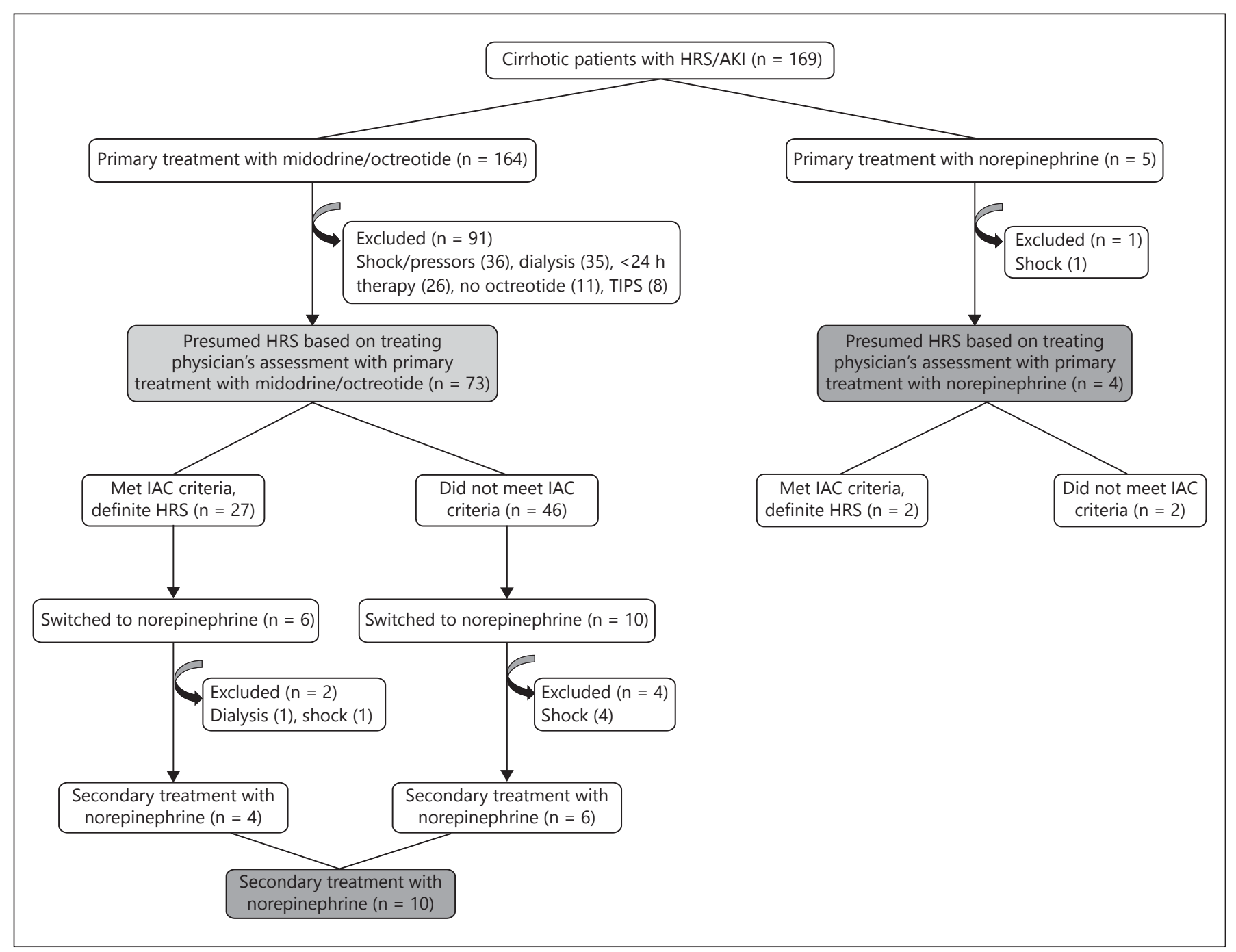

Fig. 1. Flow diagram of the study protocol designed to identify a cohort of patients with HRS treated with vasoconstrictors at our institution. Box filled with light gray shows the midodrine/octreotide-treated cohort $(n=73$; all primary treatment) and boxes in

spect to their maximum change in MAP, greater increases in MAP were associated with greater declines in $\mathrm{sCr}$ for both the presumed and the definite HRS cohorts (fig. 2).

\section{Norepinephrine Cohort}

For the 14 patients with presumed HRS who received treatment with norepinephrine, the starting dose of norepinephrine was $5 \mu \mathrm{g} / \mathrm{min}$ and the median peak infusion rate was $28 \mu \mathrm{g} / \mathrm{min}$ (range $5-70$ ). The observation period had a median duration of 4 days (IQR 4-6) for the presumed HRS group and 4 days (IQR 3-7) for the definite HRS. Among norepinephrine-treated patients $(n=14)$, there was a significant correlation between increase in dark gray combined show the norepinephrine-treated cohort $(\mathrm{n}=$ 4 (primary treatment) +10 (transitioned from midodrine/octreotide $=14$ ). No patient was transitioned from norepinephrine to midodrine/octreotide.

MAP and reduction serum in creatinine (beta $-0.042, \mathrm{p}=$ 0.002) (table 3). The absolute value of the beta estimate was larger in this subset than in the midodrine/octreotide cohort, suggesting that the estimated correlation between sCr change and MAP change was stronger during norepinephrine therapy. A $10 \mathrm{~mm} \mathrm{Hg}$ increase in MAP was associated with an average reduction in $\mathrm{sCr}$ of $0.42 \mathrm{mg} / \mathrm{dl}$ in this cohort. Baseline MAP, MELD score and day of HRS therapy were not predictive of creatinine change, but higher baseline sCr was associated with worsening sCr. When data were separated based on maximum change in MAP, greater increases in MAP were associated with greater declines in $\mathrm{sCr}$ (fig. 3). Of the 14 patients 
Table 1. Baseline characteristics of study participants

\begin{tabular}{|c|c|c|c|c|}
\hline Characteristic & $\begin{array}{l}\text { presumed HRS } \\
(\mathrm{n}=73)\end{array}$ & $\begin{array}{l}\text { definite HRS } \\
(\mathrm{n}=27)\end{array}$ & $\begin{array}{l}\text { presumed HRS } \\
(\mathrm{n}=14)\end{array}$ & $\begin{array}{l}\text { definite HRS } \\
(n=6)\end{array}$ \\
\hline Age, years & $54.5 \pm 10$ & $54.5 \pm 8$ & $50.7 \pm 8$ & $50.1 \pm 14$ \\
\hline Gender, male/female & $50 / 23$ & $18 / 9$ & $9 / 5$ & $4 / 2$ \\
\hline Race, white/black & $68 / 5$ & $26 / 1$ & $14 / 0$ & $6 / 0$ \\
\hline \multicolumn{5}{|l|}{ Laboratory values } \\
\hline Serum sodium, mEq/l & $131 \pm 6$ & $132 \pm 5$ & $131 \pm 5$ & $130 \pm 6$ \\
\hline Serum albumin, g/dl & $2.4 \pm 0.7$ & $2.5 \pm 0.8$ & $2.7 \pm 0.9$ & $2.5 \pm 0.5$ \\
\hline Total bilirubin, mg/dl & $10.0 \pm 11.1$ & $11.1 \pm 11.7$ & $18.6 \pm 15.1^{\mathrm{c}}$ & $18.3 \pm 17.3^{\mathrm{d}}$ \\
\hline Urine sodium $<10 \mathrm{mEq} / \mathrm{l}$ & $54(73.9)$ & $21(78)$ & $10(71.4)$ & $5(83)$ \\
\hline MAP, mm Hg & $72.7 \pm 11$ & $67.6 \pm 10$ & $76.2 \pm 9$ & $70.4 \pm 9$ \\
\hline MELD score & $32 \pm 7$ & $32 \pm 7$ & $34.4 \pm 5$ & $35 \pm 7$ \\
\hline
\end{tabular}

Data are presented as means (SD). Urine sodium $<10 \mathrm{mEq} / \mathrm{l}$, pre-therapy albumin infusion and definite HRS are presented in number of cases (\%); urine output (not available in 16/73 (21\%) and 2/14 (14\%) of the midodrine/octreotide and norepinephrine-treated patients, respectively) is presented as median (range). ${ }^{\mathrm{a}} \mathrm{p}$ value $<0.05 \mathrm{vs}$. midodrine/octreotide (presumed HRS); ${ }^{\mathrm{b}} \mathrm{p}$ value $<0.05 \mathrm{vs}$. midodrine/octreotide (definite HRS); ${ }^{\mathrm{c}} \mathrm{p}$ value $<0.01$ vs. midodrine/octreotide (presumed HRS); ${ }^{\mathrm{d}} \mathrm{p}$ value $<0.01$ vs. midodrine/octreotide (definite HRS).

Table 2. Multivariate mixed linear regression model examining the association between change in MAP and change in $\mathrm{sCr}$ in the midodrine/octreotide cohort

\begin{tabular}{lcccrl}
\hline Effect & $\begin{array}{l}\text { Beta } \\
\text { estimate }\end{array}$ & Error & $\begin{array}{l}\text { Degrees of } \\
\text { freedom }\end{array}$ & $\begin{array}{l}\mathrm{T} \\
\text { value }\end{array}$ & $\begin{array}{l}\mathrm{p} \\
\text { value }\end{array}$ \\
\hline $\begin{array}{l}\text { Presumed HRS cohort }(n=73) \\
\text { Intercept }\end{array}$ & 0.933 & 0.628 & 70 & 1.49 & 0.14 \\
MAP change & -0.014 & 0.004 & 310 & -3.54 & 0.0005 \\
sCr baseline & 0.068 & 0.076 & 310 & 0.90 & 0.3 \\
MAP baseline & -0.012 & 0.008 & 311 & -1.47 & 0.14 \\
Days of & & & & & \\
$\quad$ therapy & 0.007 & 0.030 & 69 & 0.23 & 0.82 \\
MELD score & -0.004 & 0.014 & 310 & -0.26 & 0.79 \\
\hline $\begin{array}{l}\text { Definite HRS cohort }(n=27) \\
\text { Intercept }\end{array}$ & 0.659 & 1.162 & 23 & & \\
MAP change & -0.037 & 0.011 & 118 & -3.23 & 0.002 \\
sCr baseline & 0.155 & 0.145 & 118 & 1.07 & 0.29 \\
MAP baseline & -0.009 & 0.017 & 118 & -0.53 & 0.60 \\
Days of & & & & & \\
$\quad$ therapy & 0.027 & 0.047 & 25 & 0.56 & 0.58 \\
MELD score & -0.006 & 0.025 & 118 & -0.22 & 0.83 \\
\hline
\end{tabular}

who entered the primary analysis in this subgroup, only 6 were categorized as definite HRS, but because of its small sample size, a separate statistical analysis was not performed for this subset. The clinical course of the all norepinephrine-treated patients is depicted in figure 4 .

\section{Clinical Outcomes}

Table 4 shows the outcomes of patients treated with either midodrine/octreotide or norepinephrine. Notably, the proportion of patients with a MAP rise $>15 \mathrm{~mm} \mathrm{Hg}$ or a significant decrease in $\mathrm{sCr}$ was lower in the midodrine/octreotide-treated group. In addition, urinary volume tended to increase more consistently for those with definite HRS treated with norepinephrine. No difference in death or dialysis was seen.

\section{Discussion}

This study provides several findings of clinical importance to HRS management. First, these data suggest that midodrine/octreotide therapy may have a significantly lower efficacy rate than previous studies have reported $[10,13,29]$. Additionally, midodrine/octreotide therapy fails to accomplish the primary goal of raising MAP in a large percentage of patients with hepatorenal AKI. Moreover, our findings demonstrate a significant correlation between the magnitude of the increase in MAP and improvement in kidney function during either midodrine/ octreotide or norepinephrine therapy for hepatorenal AKI. These results are in agreement with previous reports demonstrating a relationship between MAP gain and renal outcomes [20-22, 30]. Because our findings were gen- 
Fig. 2. a, b Correlation between MAP change and kidney function during midodrine/octreotide therapy. The largest MAP change was divided into quartiles and plotted against the subsequent change (1 day following peak MAP change) in sCr in patients with HRS treated with midodrine/ octreotide in the presumed HRS cohort $(\mathrm{n}=73 ; \mathbf{a})$ and the definite HRS cohort $(\mathrm{n}=$ 27 ; b). Bar graphs represent mean values and error bars represent 95\% CI (means (SD)). * $\mathrm{p}$ values for the correlations obtained by GLMMs, which included adjustment for covariates (i.e., baseline sCr, baseline MAP, days on therapy and MELD score).

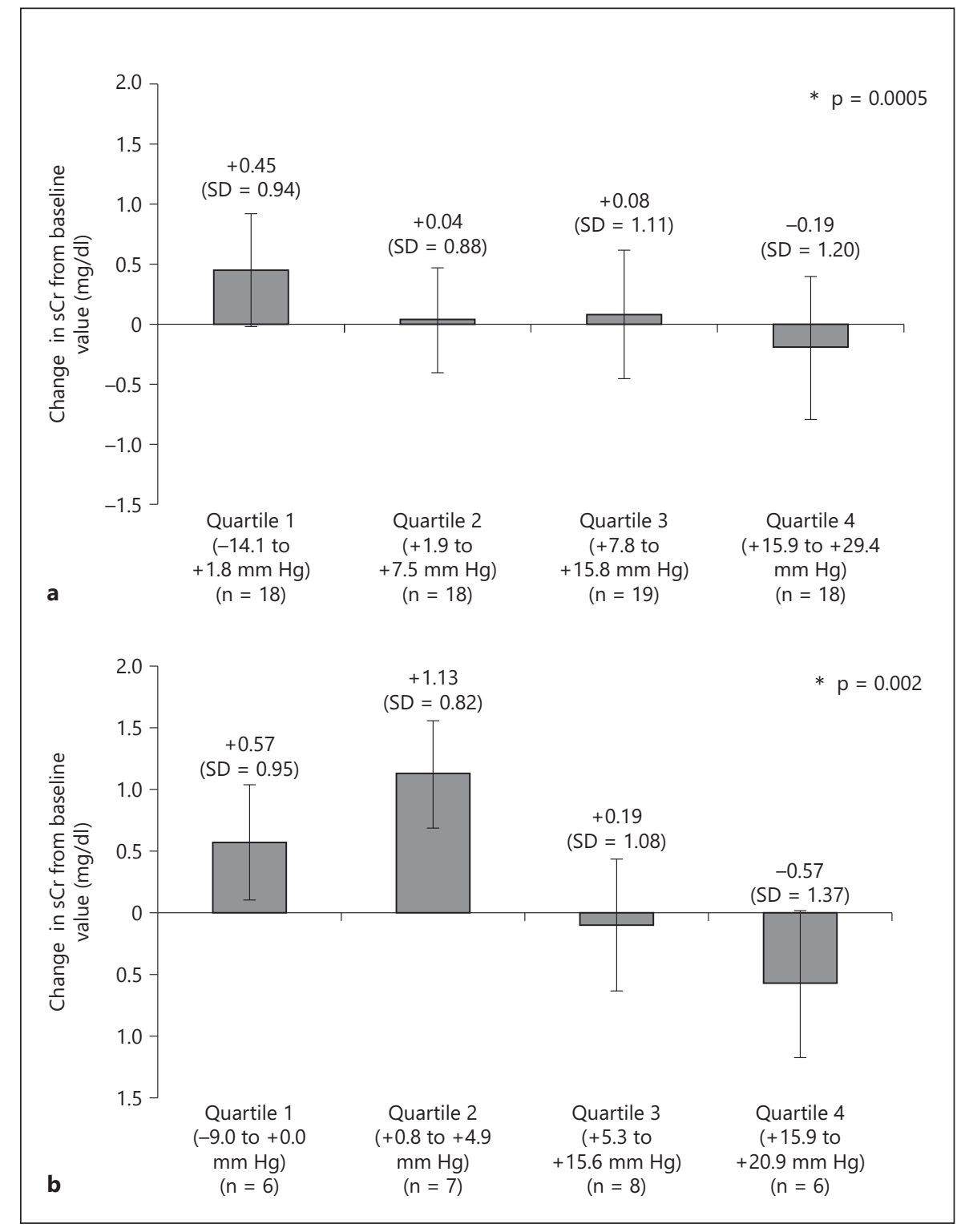

erated from a large number of data points per patient and from close examination of a wide range of MAP changes, the signal detected was robust and strengthens the notion of MAP gain as a therapeutic target. Additionally, our data are derived from a cohort reflecting actual clinical practice. The association was present regardless of the baseline value of MAP or MELD score. As other forms of intrinsic AKI are not expected to improve as a result of increasing MAP beyond 70-75 $\mathrm{mm} \mathrm{Hg}$ [31-34], the observed correlation appears to be a distinct feature of hepatorenal AKI. Furthermore, as discussed below, the magnitude of the rise in MAP appears to be of particular importance. As a surrogate of kidney function, we used $\mathrm{sCr}$ concentration. Although sCr in critically ill patients can be influenced by fluid balance [35], loss of muscle mass and other factors, it may reflect changes in kidney function in most patients.

A potential explanation for our findings may lie in the mechanistic underpinnings of HRS. The particular importance of MAP in determining renal perfusion pressure with HRS is highlighted by studies demonstrating that HRS subjects may experience a pathological linearization of the renal autoregulatory curve. In dogs subjected to carotid artery ligation, Persson et al. [36] demonstrated that overactivation of the sympathetic nervous system results in a rightward shift of the renal autoregulatory curve increasing 


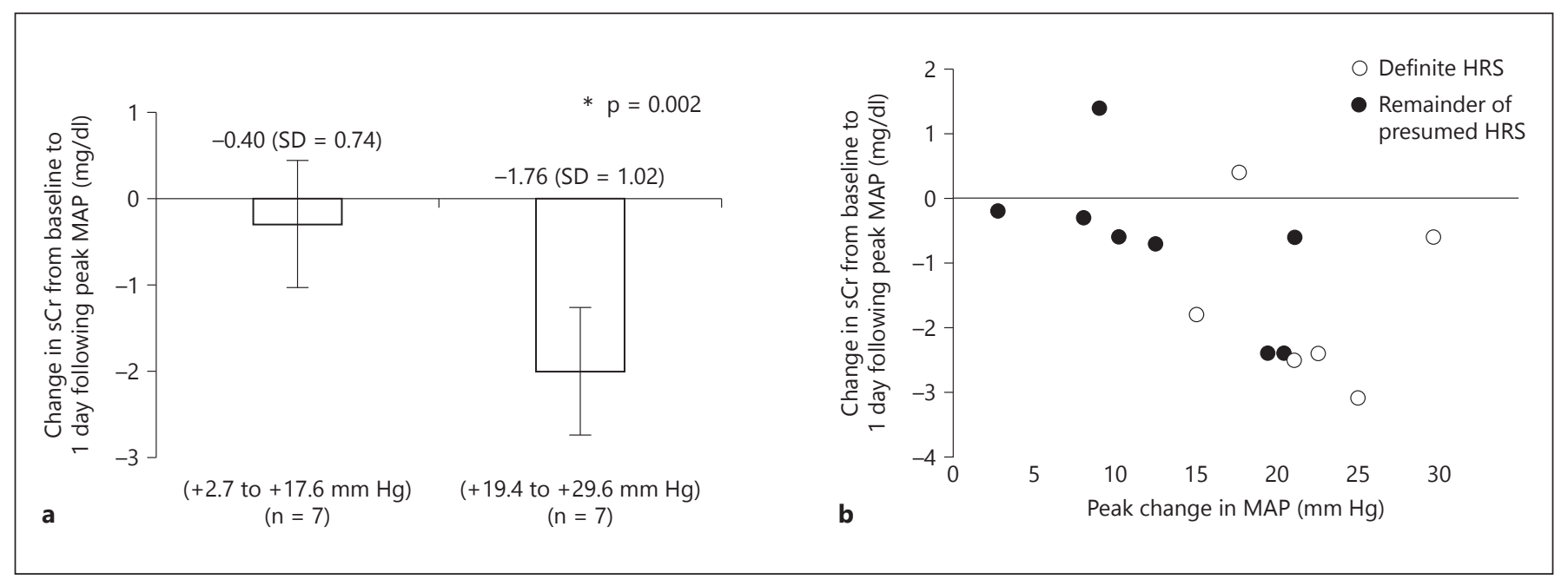

Fig. 3. a, b Correlation between MAP change and kidney function during norepinephrine therapy. Associations between the largest MAP change and the subsequent change (1 day following peak MAP change) in sCr in patients with HRS treated with norepinephrine $(\mathrm{n}=14)$ represented in MAP values below and above the

Table 3. Multivariate mixed linear regression model examining the association between change in MAP and change in $\mathrm{sCr}$ in the norepinephrine cohort

\begin{tabular}{llllll}
\hline Effect & $\begin{array}{l}\text { Beta } \\
\text { estimate }\end{array}$ & Error & $\begin{array}{l}\text { Degrees of } \\
\text { freedom }\end{array}$ & $\begin{array}{l}\mathrm{T} \\
\text { value }\end{array}$ & $\begin{array}{l}\mathrm{p} \\
\text { value }\end{array}$ \\
\hline $\begin{array}{l}\text { Presumed HRS cohort }(n=14)^{\mathrm{a}, \mathrm{b}} \\
\text { Intercept }\end{array}$ & -3.587 & 2.231 & 10 & & \\
MAP change & -0.042 & 0.013 & 33 & -1.61 & 0.14 \\
sCr baseline & 0.302 & 0.144 & 33 & 2.10 & 0.002 \\
$\begin{array}{l}\text { MAP baseline } \\
\text { Days of }\end{array}$ & 0.039 & 0.024 & 33 & 1.60 & 0.12 \\
$\quad$ therapy & -0.144 & 0.144 & 13 & -1.00 & 0.34 \\
MELD score & -0.005 & 0.031 & 33 & -0.15 & 0.88 \\
\hline
\end{tabular}

${ }^{a}$ Includes those who failed midodrine/octreotide prior to receiving norepinephrine $(\mathrm{n}=10)$ and those who were treated de novo $(\mathrm{n}=4) ;{ }^{\mathrm{b}} 6$ out of the 14 patients qualified as definite HRS.

the lower limit of autoregulation from $\sim 63$ to $91 \mathrm{~mm} \mathrm{Hg}$ for renal blood flow and from $\sim 77$ to $102 \mathrm{~mm} \mathrm{Hg}$ for glomerular filtration rate. Applying those observations to cirrhotic subjects, a similar dependency of renal blood flow on renal perfusion pressure was later demonstrated to be more pronounced among cirrhotics with HRS [37]. Therefore, we speculate that large increases in MAP during vasoconstrictor therapy HRS may allow overcoming the pathological resetting of the renal autoregulatory curve. median (a) and as a correlation graph (b). Bar graphs represent mean values and error bars represent $95 \%$ CI (means (SD)). * $\mathrm{p}$ value for the correlation obtained by GLMMs, which included adjustment for covariates (i.e., baseline $\mathrm{sCr}$, baseline MAP, days on therapy and MELD score).

Within the midodrine/octreotide cohort, the analysis restricted to patients who fulfilled the IAC criteria for HRS revealed even a stronger correlation between MAP increase and positive renal outcome. Nevertheless, we consider the analysis of the presumed HRS cohort of value as it is representative of actual clinical practice. While a set of criteria is intended to guide physicians to correctly identify patients with HRS, clinical scenarios of patients with AKI in the setting of liver cirrhosis are often cloudy, and even with available diagnostic criteria, reaching a unanimous diagnosis is frequently a challenging task, and there is no gold standard for the diagnosis of HRS. In our study, a significant fraction of patients from the presumed HRS cohort did not qualify to be categorized as definite HRS because of minor urinary abnormalities or abnormal findings on renal ultrasound. In many instances, prior laboratory values and/or radiology reports were not available to determine the acuity of those findings. Because many individuals with liver cirrhosis may have an underlying chronic renal parenchymal disease, we may have disqualified subjects with true acute hepatorenal physiology that was superimposed over an underlying chronic renal pathology $[38,39]$ scenarios that have been termed type 3 HRS $[40,41]$. Therefore, to account for that uncertainty, we termed our presumed HRS population as a more global category of hepatorenal AKI.

Norepinephrine induces vasoconstriction of the renal vasculature and, as such, its efficacy in HRS is somewhat 
Fig. 4. a, b Individual patient data demonstrating the trajectory of sCr over time (a) as well as the trajectory of MAP over time (b) during administration of norepinephrine when used as 'rescue therapy' after failure to respond to midodrine/octreotide $(\mathrm{n}=10)$ or as 'de novo therapy' $(\mathrm{n}=4)$ for presumed HRS. De novo patients were marked with hollow circles. Blue lines show the course of patients who had a $>25 \%$ decrease in $\mathrm{sCr}$ at the end of therapy (8 out of 14) and orange lines show those who did not exhibit such improvement (6 out of 14). Dashed vertical lines mark the first day of treatment with norepinephrine.

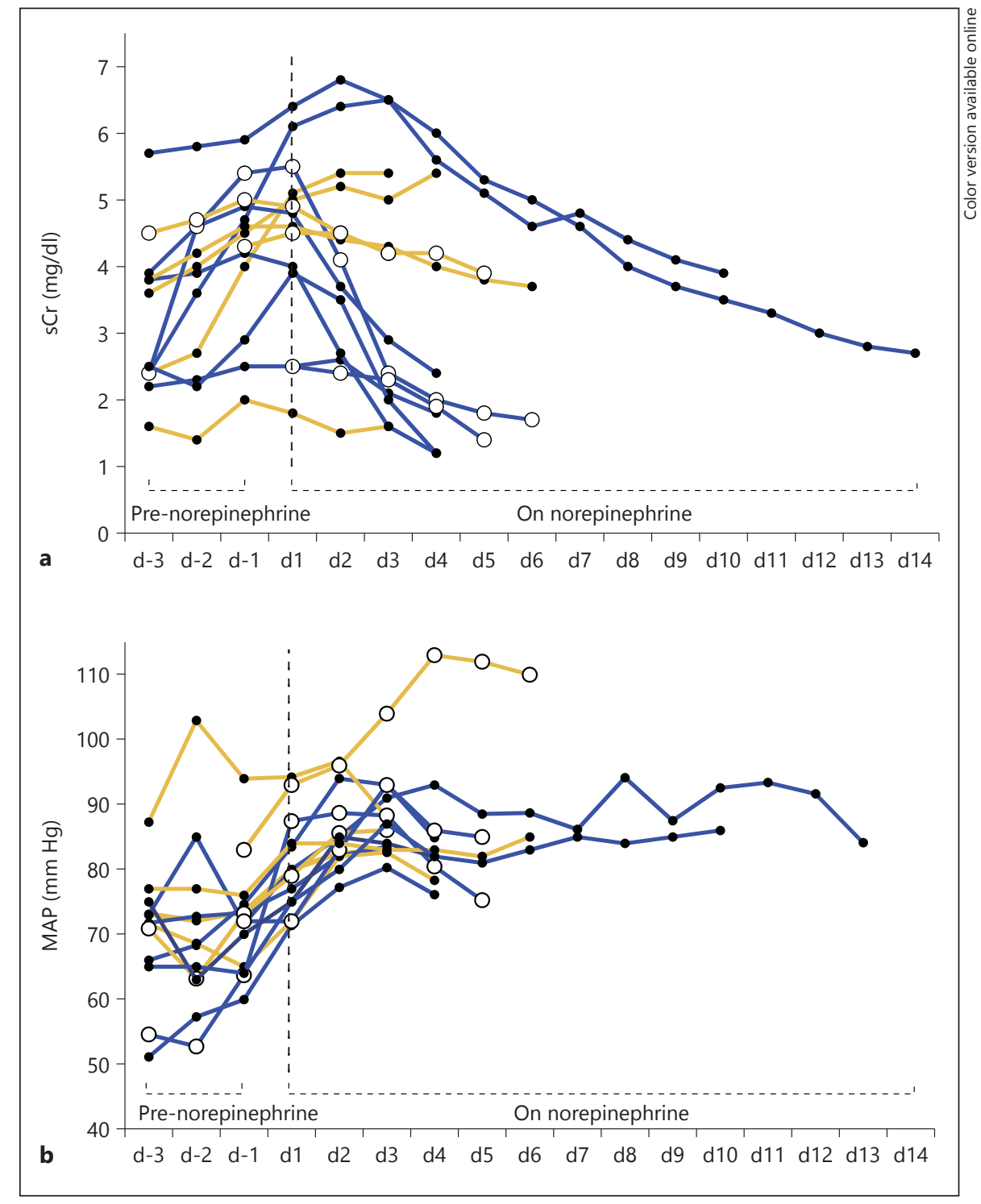

counterintuitive. As a result, it has not been widely adopted as treatment for HRS despite 4 head-to-head controlled trials demonstrating equivalent efficacy to terlipressin $[7,8,42,43]$. As observed in the midodrine/octreotide cohort, we found a significant correlation between the magnitude of the rise in MAP and the decrease in $\mathrm{sCr}$. Moreover, the correlation was stronger in norepinephrine-treated patients. However, the sample size of the norepinephrine-treated subset is small. Furthermore, a selection bias cannot be excluded because only a fraction of midodrine/octreotide-treated patients went on to receive norepinephrine and a true crossover was not feasible. Patients' eligibility for liver transplantation may have influenced the enthusiasm of the treating physician to transition the treatment to norepinephrine. Unlike our study, a recent prospective study found comparable efficacy of norepinephrine and midodrine/octreotide in 23 subjects with HRS [44]. Importantly, the attained rise in MAP was also similar between groups, an aspect that lends further support to our findings that MAP gain is a key predictor of treatment response. The inconsistent rise in MAP in our midodrine/octreotide-treated patients may reflect therapeutic inertia, inadequate awareness of the importance of pursuing dose up-titration, inconsistent use of albumin infusion or attenuated vasopressor effect in our patient population due to disease severity. The erratic performance of midodrine/octreotide as vasoconstrictor therapy has led to a temporal trend to an 
Table 4. Comparison of clinical outcomes between midodrine/octreotide and norepinephrine-treated patients

\begin{tabular}{|c|c|c|c|c|}
\hline & \multicolumn{2}{|c|}{ Midodrine/octreotide } & \multicolumn{2}{|l|}{ Norepinephrine } \\
\hline & $\begin{array}{l}\text { presumed HRS } \\
(\mathrm{n}=73)\end{array}$ & $\begin{array}{l}\text { definite HRS } \\
(\mathrm{n}=27)\end{array}$ & $\begin{array}{l}\text { presumed HRS } \\
(\mathrm{n}=14)\end{array}$ & $\begin{array}{l}\text { definite HRS } \\
(\mathrm{n}=6)\end{array}$ \\
\hline$\uparrow \mathrm{MAP}>15 \mathrm{~mm} \mathrm{Hg}^{\mathrm{a}}$ & $19(26.0)$ & $7(25.9)$ & $9(64.2)^{\mathrm{c}}$ & $6(100.0)^{\mathrm{d}}$ \\
\hline Transitioned to norepinephrine & $11(15.1)$ & $4(14.8)$ & - & - \\
\hline$>50 \% \downarrow$ in $\mathrm{sCr}^{\mathrm{a}}$ & $11(15.1)$ & $4(14.8)$ & $6(42.9)^{\mathrm{e}}$ & $3(50.0)$ \\
\hline$>25 \% \downarrow$ in $\mathrm{sCr}$ by $48 \mathrm{~h}$ & $7(9.6)$ & $3(11.1)$ & $4(28.6)$ & $2(33.3)$ \\
\hline$>100 \% \uparrow$ in urine volume by $48 \mathrm{~h}^{\mathrm{b}}$ & $21 / 63(33.3)$ & $5 / 20(25)$ & $5 / 12(41.7)$ & $3 / 5(60.0)$ \\
\hline Need for dialysis & $14(19.1)$ & $5(18.5)$ & $2(14.3)$ & $1(16.7)$ \\
\hline Discharged home & $23(31.5)$ & $11(40.7)$ & $3(21.4)$ & $2(33.3)$ \\
\hline Discharged as ESRD & $4(5.5)$ & $2(7.4)$ & $1(7.1)$ & $1(16.7)$ \\
\hline Underwent OLT & $7(9.6)$ & $1(3.7)$ & $2(14.3)$ & $1(16.7)$ \\
\hline Death & $14(19.2)$ & $5(18.5)$ & $5(35.7)$ & $1(16.7)$ \\
\hline Palliative & $16(21.9)$ & $4(14.8)$ & $4(28.6)$ & $2(33.3)$ \\
\hline
\end{tabular}

Data are presented as number of cases (\%). ESRD = End-stage renal disease; OLT = orthotopic liver transplantation.

a At any point during therapy; ${ }^{\mathrm{b}}$ accurate daily urine volume was not available in all patients; ${ }^{\mathrm{c}} \mathrm{p}$ value $=0.01 \mathrm{vs}$. midodrine/octreotide (presumed HRS); ${ }^{\mathrm{d}} \mathrm{p}$ value $<0.005$ vs. midodrine/octreotide (definite HRS); ${ }^{\mathrm{e}} \mathrm{p}$ value $<0.05$ vs. midodrine/octreotide (presumed HRS).

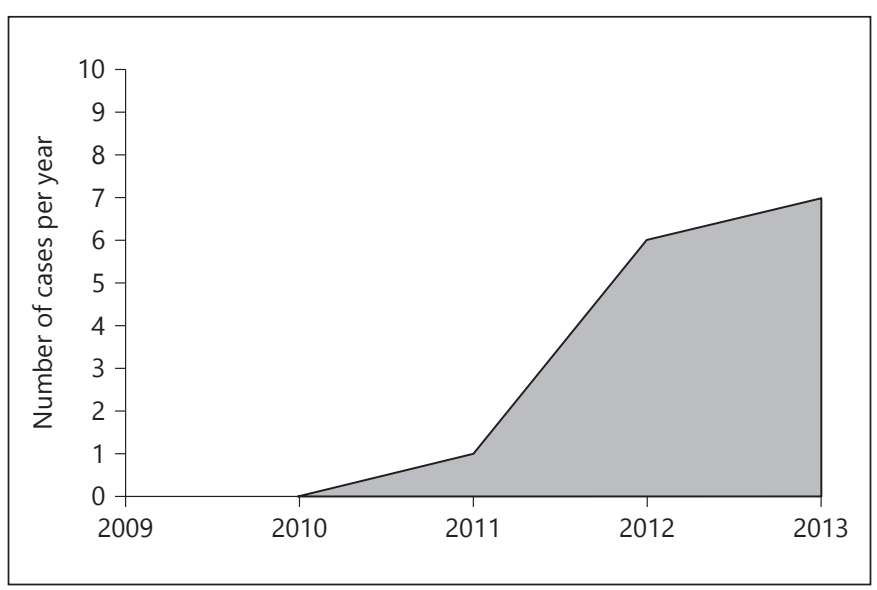

Fig. 5. Temporal distribution of usage of norepinephrine in cirrhotics with presumed HRS in our university hospital.

increased use of norepinephrine in our institution (fig. 5). Norepinephrine is a more potent vasoconstrictor, is more rapidly titratable than midodrine and its use inherently requires more intense blood pressure monitoring.

If MAP increase is the most important determinant of recovery of renal function, then identifying the minimum required MAP elevation is an important goal. A previous study found that a $5 \mathrm{~mm} \mathrm{Hg}$ of rise in MAP by day 3 during terlipressin therapy was associated with an OR of 9.3 for HRS reversal [21]. However, that relationship seemed lost after adjustment for serum bilirubin. Others have shown that a MAP gain $>10 \mathrm{~mm} \mathrm{Hg}$ might be associated with a positive renal outcome $[30,45]$. Moreover, clinical trials assessing the use of norepinephrine have been designed to target a rise in MAP of $10 \mathrm{~mm} \mathrm{Hg}$. Our study was not designed to search for a specific cutoff value. However, our observations suggest that an appropriate cutoff might be around $15 \mathrm{~mm} \mathrm{Hg}$, as individuals who experienced this change tended to have a significantly greater improvement in sCr (fig. 2 and 3). Of note, the seminal study by Angeli et al. [10], which first demonstrated the efficacy of midodrine/octreotide therapy in HRS, required a dose up-titration with a goal of achieving a $15 \mathrm{~mm} \mathrm{Hg}$ rise in MAP. Interestingly, only $26 \%$ of midodrine/octreotide-treated patients in our cohort achieved a rise in MAP of $15 \mathrm{~mm} \mathrm{Hg}$ or higher.

Our study has several limitations. First, its retrospective design does not allow for the determination of causality. Second, because it is an observational single-center study, it may not be entirely generalizable to all centers where HRS patients are medically managed. Third, although the association between gain in MAP and improvement in renal outcome was found to be statistically significant, the absolute change in $\mathrm{sCr}$ was somewhat modest as demonstrated by the beta estimates. However, the magnitude of the observed correlation was more robust for the definite HRS cohort, suggesting that misclassification of HRS could have partially accounted for the more modest benefit seen in the presumed HRS cohort. Fourth, cirrhotic individuals with HRS and tense 
ascites are known to have increased intra-abdominal pressure (IAP). In that setting, renal perfusion pressure corresponds to the difference between MAP and IAP. Because IAP was not systematically measured in our cohort, we cannot determine whether the presence of intra-abdominal hypertension in some subjects may have attenuated the net effect of a MAP rise and influenced our results. Finally, only $25 \%$ of patients in our cohort were concomitantly treated with daily intravenous albumin despite current guidelines for HRS management. Therefore, our findings may not be generalizable to treatments that include simultaneous albumin infusion.

In summary, our findings demonstrate an association between the magnitude of an attained rise in MAP and improvement in kidney function during vasoconstrictor therapy for hepatorenal AKI. Although a fairly intuitive notion, it remains underexploited in clinical grounds. This report calls for attention to this neglected principle. Our data suggest that norepinephrine might be more effective in both consistently raising MAP and reverting hepatorenal AKI compared to midodrine/octreotide combination. However, a large-scale prospective randomized study would be needed to confirm these findings as well as to evaluate its cost and risk-benefit ratio. In addition, the minimum required MAP elevation to achieve a beneficial effect of kidney function remains speculative and would also require a prospective study to confirm.

\section{Acknowledgments}

Part of this work was presented in as a poster at the American Society of Nephrology Kidney Week, in November of 2014, in Philadelphia, PA.

This project was supported by grants from the National Institutes of Health (NCATS UL1TR000062 for P.J.N. and A.J.G., and NCATS KL2TR000060 for A.J.G.).

\section{Authors' Contributions}

J.C.Q.V., M.K., M.T., N.K. and T.M.W. conceived and designed the study; M.K., M.T., N.M.B. and T.A.D. performed data collection; P.J.N. analyzed the data; J.C.Q.V., N.K., D.C.R. and A.J.G. interpreted results and elaborated discussion; J.C.Q.V., D.C.R., P.J.N. and A.J.G. wrote the paper. All the authors reviewed and approved the manuscript.

\section{Disclosure Statement}

J.C.Q.V. has served in an Advisory Board Panel for Mallinckrodt Pharmaceuticals in a topic unrelated to this manuscript.

\section{References}

1 Gines A, Escorsell A, Gines P, Salo J, Jimenez W, Inglada L, Navasa M, Claria J, Rimola A, Arroyo V, et al: Incidence, predictive factors, and prognosis of the hepatorenal syndrome in cirrhosis with ascites. Gastroenterology 1993; 105:229-236.

- Warner NS, Cuthbert JA, Bhore R, Rockey DC: Acute kidney injury and chronic kidney disease in hospitalized patients with cirrhosis. J Investig Med 2011;59:1244-1251.

- 3 Kiser TH, Fish DN, Obritsch MD, Jung R, MacLaren R, Parikh CR: Vasopressin, not octreotide, may be beneficial in the treatment of hepatorenal syndrome: a retrospective study. Nephrol Dial Transplant 2005;20:18131820.

4 Mulkay JP, Louis H, Donckier V, Bourgeois N, Adler M, Deviere J, Le Moine O: Longterm terlipressin administration improves renal function in cirrhotic patients with type 1 hepatorenal syndrome: a pilot study. Acta Gastroenterol Belg 2001;64:15-19.

5 Ortega R, Gines P, Uriz J, Cardenas A, Calahorra B, De Las Heras D, Guevara M, Bataller R, Jimenez W, Arroyo V, Rodes J: Terlipressin therapy with and without albumin for pa- tients with hepatorenal syndrome: results of a prospective, nonrandomized study. Hepatology 2002;36:941-948.

6 Uriz J, Gines P, Cardenas A, Sort P, Jimenez W, Salmeron JM, Bataller R, Mas A, Navasa M, Arroyo V, Rodes J: Terlipressin plus albumin infusion: an effective and safe therapy of hepatorenal syndrome. J Hepatol 2000;33:4348.

7 Alessandria C, Ottobrelli A, Debernardi-Venon W, Todros L, Cerenzia MT, Martini S, Balzola F, Morgando A, Rizzetto M, Marzano A: Noradrenalin vs terlipressin in patients with hepatorenal syndrome: a prospective, randomized, unblinded, pilot study. J Hepatol 2007;47:499-505.

8 Sharma P, Kumar A, Shrama BC, Sarin SK: An open label, pilot, randomized controlled trial of noradrenaline versus terlipressin in the treatment of type 1 hepatorenal syndrome and predictors of response. Am J Gastroenterol 2008;103:1689-1697.

-9 Duvoux C, Zanditenas D, Hezode C, Chauvat A, Monin JL, Roudot-Thoraval F, Mallat A, Dhumeaux D: Effects of noradrenalin and albumin in patients with type I hepatorenal syndrome: a pilot study. Hepatology 2002;36: 374-380.

10 Angeli P, Volpin R, Gerunda G, Craighero R, Roner P, Merenda R, Amodio P, Sticca A, Caregaro L, Maffei-Faccioli A, Gatta A: Reversal of type 1 hepatorenal syndrome with the administration of midodrine and octreotide. Hepatology 1999;29:1690-1697.

-11 Esrailian E, Pantangco ER, Kyulo NL, Hu KQ, Runyon BA: Octreotide/midodrine therapy significantly improves renal function and 30 day survival in patients with type 1 hepatorenal syndrome. Dig Dis Sci 2007;52:742-748.

12 Kalambokis G, Economou M, Fotopoulos A, Al Bokharhii J, Pappas C, Katsaraki A, Tsianos EV: The effects of chronic treatment with octreotide versus octreotide plus midodrine on systemic hemodynamics and renal hemodynamics and function in nonazotemic cirrhotic patients with ascites. Am J Gastroenterol 2005; 100:879-885.

$\checkmark 13$ Skagen C, Einstein M, Lucey MR, Said A: Combination treatment with octreotide, midodrine, and albumin improves survival in patients with type 1 and type 2 hepatorenal syndrome. J Clin Gastroenterol 2009;43:680-685. 
14 Gines P, Guevara M, Arroyo V, Rodes J: Hepatorenal syndrome. Lancet 2003;362:18191827.

15 Lenz K, Buder R, Kapun L, Voglmayr M: Treatment and management of ascites and hepatorenal syndrome: an update. Therap Adv Gastroenterol 2015;8:83-100.

- 16 Sanyal AJ, Boyer T, Garcia-Tsao G, Regenstein F, Rossaro L, Appenrodt B, Blei A, Gulberg V, Sigal S, Teuber P; Terlipressin Study Group: A randomized, prospective, doubleblind, placebo-controlled trial of terlipressin for type 1 hepatorenal syndrome. Gastroenterology 2008;134:1360-1368.

17 Londono MC, Abraldes JG, Altamirano J, Decaens T, Forns X: Clinical trial watch: reports from the AASLD liver Meeting ${ }^{\circledR}$, Boston, November 2014. J Hepatol 2015;62: 1196-1203.

18 Runyon BA; AASLD: Introduction to the revised American association for the study of liver diseases practice guideline management of adult patients with ascites due to cirrhosis 2012. Hepatology 2013;57:1651-1653.

19 Cavallin M, Kamath PS, Merli M, Fasolato S, Toniutto P, Salerno F, Bernardi M, Romanelli RG, Colletta C, Salinas F, Di Giacomo A, Ridola L, Fornasiere E, Caraceni P, Morando F, Piano S, Gatta A, Angeli P; Italian Association for the Study of the Liver Study Group on Hepatorenal Syndrome: Terlipressin plus albumin versus midodrine and octreotide plus albumin in the treatment of hepatorenal syndrome: a randomized trial. Hepatology 2015; 62:567-574

20 Velez JC, Nietert PJ: Therapeutic response to vasoconstrictors in hepatorenal syndrome parallels increase in mean arterial pressure: a pooled analysis of clinical trials. Am J Kidney Dis 2011;58:928-938.

-21 Nazar A, Pereira GH, Guevara M, MartínLlahi M, Pepin MN, Marinelli M, Solá E, Baccaro ME, Terra C, Arroyo V, Ginès P: Predictors of response to therapy with terlipressin and albumin in patients with cirrhosis and type 1 hepatorenal syndrome. Hepatology 2010;51:219-226.

-22 Boyer TD, Sanyal AJ, Garcia-Tsao G, Blei A, Carl D, Bexon AS, Teuber P; Terlipressin Study Group: Predictors of response to terlipressin plus albumin in hepatorenal syndrome (HRS) type 1: relationship of serum creatinine to hemodynamics. J Hepatol 2011, 55:315-321.

23 Sharma P, Kumar A, Shrama BC, Sarin SK: An open label, pilot, randomized controlled trial of noradrenaline versus terlipressin in the treatment of type 1 hepatorenal syndrome and predictors of response. Am J Gastroenterol 2008;103:1689-1697.
24 Alessandria C, Ottobrelli A, Debernardi-Venon W, Todros L, Cerenzia MT, Martini S, Balzola F, Morgando A, Rizzetto M, Marzano A: Noradrenalin vs terlipressin in patients with hepatorenal syndrome: a prospective, randomized, unblinded, pilot study. J Hepatol 2007;47:499-505.

25 Salerno F, Gerbes A, Ginès P, Wong F, Arroyo $\mathrm{V}$ : Diagnosis, prevention and treatment of hepatorenal syndrome in cirrhosis. Gut 2007; 56:1310-1318.

26 Arroyo V, Ginès P, Gerbes AL, Dudley FJ, Gentilini P, Laffi G, Reynolds TB, Ring-Larsen $\mathrm{H}$, Schölmerich J: Definition and diagnostic criteria of refractory ascites and hepatorenal syndrome in cirrhosis. International ascites club. Hepatology 1996;23:164-176.

27 Fitzmaurice GM, Laird NM, Ware JH: Applied Longitudinal Analysis. Hoboken, Wiley-Interscience, 2004.

28 Akakie H: A new look at the statistical model identification. IEEE Trans Automatic Control 1974;19:716-723.

29 Wong F, Pantea L, Sniderman K: Midodrine, octreotide, albumin, and TIPS in selected patients with cirrhosis and type 1 hepatorenal syndrome. Hepatology 2004;40:55-64.

30 Maddukuri G, Cai CX, Munigala S, Mohammadi F, Zhang Z: Targeting an early and substantial increase in mean arterial pressure is critical in the management of type 1 hepatorenal syndrome: a combined retrospective and pilot study. Dig Dis Sci 2014;59:471-481.

- 31 Haase M, Bellomo R, Story D, Letis A, Klemz $\mathrm{K}$, Matalanis G, Seevanayagam S, Dragun D, Seeliger E, Mertens PR, Haase-Fielitz A: Effect of mean arterial pressure, haemoglobin and blood transfusion during cardiopulmonary bypass on post-operative acute kidney injury. Nephrol Dial Transplant 2012;27: 153-160.

32 Redfors B, Bragadottir G, Sellgren J, Sward K, Ricksten SE: Effects of norepinephrine on renal perfusion, filtration and oxygenation in vasodilatory shock and acute kidney injury. Intensive Care Med 2011;37:60-67.

33 Bourgoin A, Leone M, Delmas A, Garnier F, Albanese J, Martin C: Increasing mean arterial pressure in patients with septic shock: effects on oxygen variables and renal function. Crit Care Med 2005;33:780-786

34 Dunser MW, Ruokonen E, Pettila V, Ulmer $\mathrm{H}$, Torgersen C, Schmittinger CA, Jakob S, Takala J: Association of arterial blood pressure and vasopressor load with septic shock mortality: a post hoc analysis of a multicenter trial. Crit Care 2009;13:R181.

35 Liu KD, Thompson BT, Ancukiewicz M, Steingrub JS, Douglas IS, Matthay MA, Wright P, Peterson MW, Rock P, Hyzy RC, Anzueto
A, Truwit JD; National Institutes of Health National Heart, Lung, Blood Institute Acute Respiratory Distress Syndrome Network: Acute kidney injury in patients with acute lung injury: impact of fluid accumulation on classification of acute kidney injury and associated outcomes. Crit Care Med 2011;39: 2665-2671.

36 Persson PB, Ehmke H, Nafz B, Kirchheim HR: Sympathetic modulation of renal autoregulation by carotid occlusion in conscious dogs. Am J Physiol 1990;258(2 pt 2):F364F370.

37 Stadlbauer V, Wright GA, Banaji M, Mukhopadhya A, Mookerjee RP, Moore K, Jalan R: Relationship between activation of the sympathetic nervous system and renal blood flow autoregulation in cirrhosis. Gastroenterology 2008;134:111-119.

- 38 Crawford DH, Endre ZH, Axelsen RA, Lynch SV, Balderson GA, Strong RW, Kerlin P, Powell LW, Fleming SJ: Universal occurrence of glomerular abnormalities in patients receiving liver transplants. Am J Kidney Dis 1992; 19:339-344.

39 Axelsen RA, Crawford DH, Endre ZH, Lynch SV, Balderson GA, Strong RW, Fleming SJ: Renal glomerular lesions in unselected patients with cirrhosis undergoing orthotopic liver transplantation. Pathology 1995;27:237246

40 Rajekar H, Chawla Y: Terlipressin in hepatorenal syndrome: evidence for present indications. J Gastroenterol Hepatol 2011;26(suppl 1):109-114.

41 Magrico R, Mateus A, Ramos A: Whats new in hepatorenal syndrome? An updated review for the nephrologist. Port J Nephrol Hypert 2013;27:249-260.

42 Singh V, Ghosh S, Singh B, Kumar P, Sharma N, Bhalla A, Sharma AK, Choudhary NS, Chawla Y, Nain CK: Noradrenaline vs. terlipressin in the treatment of hepatorenal syndrome: a randomized study. J Hepatol 2012; 56:1293-1298.

43 Ghosh S, Choudhary NS, Sharma AK, Singh B, Kumar P, Agarwal R, Sharma N, Bhalla A, Chawla YK, Singh V: Noradrenaline vs. terlipressin in the treatment of type 2 hepatorenal syndrome: a randomized pilot study. Liver Int 2013;33:1187-1193.

44 Tavakkoli H, Yazdanpanah K, Mansourian M: Noradrenalin versus the combination of midodrine and octreotide in patients with hepatorenal syndrome: randomized clinical trial. Int J Prev Med 2012;3:764-769.

45 Cai CX, Maddukuri G, Jaipaul N, Zhang Z: A treat-to-target concept to guide the medical management of hepatorenal syndrome. Dig Dis Sci 2014;60:1474-1481. 